\title{
The COVID-19 pandemic has thrown the SDGs into reverse: The financial sector can play its part in the recovery by excluding tobacco
}

\section{Gail Hurley}

The United Nations has warned that the COVID-19 pandemic threatens to reverse decades of progress on poverty reduction, inequality, hunger, health, and education. It has described the pandemic as the worst human and economic crisis of our lifetime with the result that the UN's 17 Sustainable Development Goals (SDGs) are now even further out of reach ${ }^{1}$. It has called for 'political leadership, solidarity and unity' to overcome the crisis, and has expressly called on the private sector and financial institutions to ensure that every investment decision they make supports an inclusive and sustainable recovery and takes into account Social, Environmental and Governance (ESG) factors ${ }^{2}$. While the focus is often on the tobacco control measures that governments should and must take, the financial sector must also play its part to support a new type of economy - one which protects both people and the planet, and advances the SDGs.

\section{How tobacco negatively impacts the SDGs}

Tobacco production and consumption are incompatible with the achievement of the SDGs. Indeed, our work at Tobacco Free Portfolios shows that tobacco negatively impacts 14 of the $17 \mathrm{SDG}^{3}$. Tobacco kills an estimated 8 million people per year and is the single largest cause of preventable death worldwide, limiting progress on SDG 3 on health and wellbeing. It also kills or disables people in their prime productive years, negatively affecting SDG 8 on economic growth. In some low-income countries like Malawi and Zambia, tobacco - a crop which has no nutritional value - has displaced food crops, leading to increased food insecurity (affecting SDG 2 on zero hunger). In many of those same countries, children are forced to work in tobacco fields, limiting their educational opportunities and life chances (SDG 4 on education). We also see that tobacco consumption worsens inequalities both between and within countries since smoking is more prevalent in developing countries (where public health systems are less able to cope) as well as within disadvantaged communities in all countries (SDG 10 on reduced inequalities). Tobacco production also leads to biodiversity loss, land pollution, soil degradation and deforestation, all of which reduce progress towards SDG 13 on climate action and SDG 15 on life on land. Meanwhile, an estimated 4.5 trillion cigarette filters are discarded every year, many of which end up in oceans and beaches, negatively impacting SDG 14 (life under water). The list goes on. Tobacco is therefore simultaneously a public health issue, an equality issue, a human rights issue, an international development issue, an environmental issue and a climate change issue.

The financial sector has meanwhile made laudable commitments to support
AFFILIATION

1 Tobacco Free Portfolios, Edinburgh, United Kingdom

CORRESPONDENCE TO

Gail Hurley. Tobacco Free Portfolios, Edinburgh, United Kingdom.

E-mail: gh@tobaccofreeportfolios. org

KEYWORDS

tobacco control, SDGs, financial sector, tobacco free finance

Received: 30 July 2021 Accepted: 3 August 2021 
the SDGs. These must be backed by action on tobacco.

Finance sector actors wield enormous power worldwide with their investment, lending and insurance decisions. For example, pension funds alone held over US\$35 trillion in assets at the end of $2020^{4}$. Globally, the insurance market generated total gross written premiums of US\$5.8 trillion in 2020, with $53 \%$ in non-life sectors ${ }^{5}$. The decisions they make can help drive finance to SDGfriendly economic activities and projects. Indeed, many finance sector actors have made public commitments to support the SDGs, as expressed by their participation in important international initiatives like the UN Global Compact ${ }^{6}$, Global Investors for Sustainable Development (GISD) ${ }^{7}$, and the UN Principles for Responsible Investment (as well as more recently the Principles for Responsible Banking and Insurance) $)^{8}$. Awareness and interest in investing 'responsibly' and 'sustainably' have increased significantly over recent years.

At the same time, we see that many banks, pension funds, insurance providers and other finance sector actors continue to lend to, invest in, and insure tobacco companies, despite their promises to support the SDGs. To be sure, there are also many leaders within financial institutions that have decided to eliminate tobacco from their portfolios. We are delighted that over 170 financial institutions across 21 countries have so far signed Tobacco Free Portfolio's Tobacco Free Finance Pledge ${ }^{9}$. But more needs to be done to ensure there is credibility and substance behind claims to be SDG-aligned.

Both the COVID-19 pandemic and the climate and environmental crises have accelerated the need for urgent action on tobacco control. All actors have a role to play, and the financial sector must play its part. Financial institutions can demonstrate their commitment to the SDGs by implementing tobacco exclusions and we invite them to join a vibrant and growing community of finance sector champions committed to tobacco-free finance.

\section{REFERENCES}

1. United Nations. UN report finds COVID-19 is reversing decades of progress on poverty, healthcare and education. Department of Economic and Social Affairs, United Nations. July 7, 2020. Accessed July 25, 2021. https:// www.un.org/development/desa/en/news/sustainable/ sustainable-development-goals-report-2020.html

2. United Nations. 'Deeply negative impact' of COVID pandemic, reverses SDG progress. UN News. July 15, 2021. Accessed July 25, 2021. https://news.un.org/en/ story/2021/07/1095942

3. Tobacco Free Portfolios. The toolkit. 12th ed. Tobacco Free Portfolios; 2020. Accessed June 15, 2021. https:// tobaccofreeportfolios.org/wp-content/uploads/2021/02/ TFP-Toolkit-12th-Edition-January-28-2021-1.pdf

4. Organisation for Economic Co-operation and Development. Global pension statistics. OECD; 2020. July 25, 2021. https://www.oecd.org/finance/ globalpensionstatistics.htm

5. Research and Markets. Insurance Global Industry Almanac 2016-2025. March 2021. ID: 5312123. Accessed July 25, 2021. https://www.researchandmarkets. com/reports/5312123/insurance-global-industryalmanac-2016-2025?utm_source=GNOM\&utm_ medium $=$ PressRelease $\&$ utm_code $=$ wp 52 c $8 \& u t m \_$ campaign=1531975+-+Global+Insurance+Industry+ Almanac+2021\%3a+Market+Share\%2c+Market+Size +Value+2016-20\%2c+and+Forecast+to+2025\&utm_ exec $=$ chdo54prd

6. United Nations Global Compact. Accessed July 25, 2021. https://www.unglobalcompact.org/

7. Global Investors for Sustainable Development. United Nations; 2021. Accessed July 25, 2021. https://www. gisdalliance.org/

8. Principles for Responsible Investment. United Nations;2021. Accessed July 25, 2021. https://www. unpri.org/

9. Tobacco Free Portfolios. The Pledge. Tobacco Free Portfolios; 2021. Accessed July 25, 2021. https:// tobaccofreeportfolios.org/the-pledge/
CONFLICTS OF INTEREST

The author has completed and submitted the ICMJE Form for Disclosure of Potential Conflicts of Interest and none was reported.

FUNDING

There was no source of funding for this research.

ETHICAL APPROVAL AND INFORMED CONSENT

Ethical approval and informed consent were not required for this study.

DATA AVAILABILITY

Data sharing is not applicable to this article as no new data were created.

PROVENANCE AND PEER REVIEW

Commissioned; internally peer reviewed. 